\title{
Does swift heavy ion beam mixing in metal/a-Ge interface result from transient thermal process?
}

\author{
Abdelhak Chettah ${ }^{1 *}$ and Hiroshi Amekura ${ }^{2}$ \\ 1 LGMM Laboratory, Functional Materials Group, Université 20 Août 1955-Skikda, BP 26, 21000 Skikda, Algeria \\ 2 National Institute for Materials Science (NIMS), Tsukuba, Ibaraki 305-0003, Japan \\ * Corresponding author: e-mail: chettah.ah@gmail.com
}

\begin{abstract}
In this paper, the inelastic thermal spike model extended to multilayered systems was applied to $\mathrm{Cu} / \mathrm{a}-\mathrm{Ge}$ system and compared to the experimental results available in literature. Evidence of molten phase formation from both sides of the interface has been identified for both the irradiations at room temperature and $77 \mathrm{~K}$. However, comparison with the experimental results reveals, in addition to liquid diffusion, a further unknown contribution to mixing for room temperature irradiations. We suggested that solid state diffusion of $\mathrm{Cu}$ atoms was enhanced in radiation-induced porous-structure in a-Ge at room temperature.
\end{abstract}

Key words: swift heavy ions, amorphous germanium, mixing, thermal spike model.

\section{INTRODUCTION}

For amorphous materials, the electronic mobility is greatly lower than the same materials in their crystalline form. They are characterized by a lower mean diffusion length of the electrons as compared with crystalline form ( $\left.\lambda_{\text {amorphous }}<\lambda_{\text {crystalline}}\right)$, and therefore, a higher electron-phonon coupling constant ( $\left.g_{\text {amorphous }}>g_{\text {crystalline }}\right)$. In fact, crystalline silicon and germanium exhibited a stiff insensitivity to high electronic excitation $\left(S_{e}\right)$ induced by monomer ion irradiation and continuous tracks could not be observed except with cluster irradiations $[1,2]$. In contrast, amorphous silicon (a-Si) and germanium (a-Ge) were found to be very sensitive to $S_{e}$ and low $S_{e}$ threshold values $\left(S_{\text {eth }}<10 \mathrm{keV} / \mathrm{nm}\right)$ were reported for ion track appearance [3-5]. It is assumed that high $S_{e}$ leads to the formation of voids [5-7] which were suggested to originate from outward shock waves resulting from the expansion of the ion track core [8], leading to the formation of a sponglike (porous) layer. Toulemonde et al. [10] have shown, in the framework of the inelastic thermal spike model (ITSM), that track occurrence in amorphous materials result from a transient process assuming that the experimental observations $[9,10]$ results from the quench of a molten phase.

Besides ion track formation, swift heavy ions (SHI) have been shown to be capable of modifying the composition and structure of thin films and their interfaces [11-16]. However, the underlying mechanisms responsible of the atomic inter-diffusion induced by electronic energy deposition remains poorly understood. So far, the majority of the investigations involving mixing by SHI irradiations assume diffusion enhancement by the liquid phase formation from both sides of the interface. Such assumption could only be verified using the ITSM extended to multilayers, in which the lattice temperature profiles along the ion path are calculated, and therefore, melting of the interface and the molten phase lifetime can be predicted. This procedure has been applied previously in different interfaces: $\mathrm{Ni} / \mathrm{Ti}$ [17], $\mathrm{Fe} /(\mathrm{Al}$ or $\mathrm{Au})$ [18], Ni/Si [19] and (Bi or $\mathrm{Au}) / \mathrm{Al}_{2} \mathrm{O}_{3}[20]$.

Recently, Kumar et al. [21] studied interface mixing induced by $\mathrm{SHI}$ irradiations in $\mathrm{Cu} / \mathrm{a}-\mathrm{Ge}$ system. The irradiated system consists of a-Ge( $87 \mathrm{~nm}) / \mathrm{Cu}(94 \mathrm{~nm})$ bilayer deposited on $\mathrm{Si}(100)$ substrate by electron beam evaporation. A thin layer of $\mathrm{Al}$ was deposited on top for protection reasons. The final structure of the samples was: $\mathrm{Al}(32 \mathrm{~nm}) / \mathrm{a}-\mathrm{Ge}(87 \mathrm{~nm}) / \mathrm{Cu}(94 \mathrm{~nm}) / \mathrm{Si}$. Table I summarizes the different irradiation parameters as well as the measured mixing rates. At $77 \mathrm{~K}$, the difference of variances $\Delta \sigma^{2}$ (the difference between RBS spectra before and after irradiation) showed a linear behavior versus the fluence $\phi$. The slope $k=\Delta \sigma^{2} / \phi$ is defined as the mixing rate, whereas at room temperature (RT), non-linear behavior was found: $\Delta \sigma^{2}=k \phi+m \phi^{2}$. The values of $k$ (mixing rate) and $m$ (reaction rate) are reported in Table I. The non-linear behavior at RT was explained by the contribution of solid state diffusion.

Table I The ion, energy, irradiation temperature, $S_{e}$ and mixing results (mixing rate $k$ and reaction rate $m$ ) of the $\mathrm{Al}(32$ $\mathrm{nm}) / \mathrm{a}-\mathrm{Ge}(87 \mathrm{~nm}) / \mathrm{Cu}(94 \mathrm{~nm}) / \mathrm{Si}$ system

\begin{tabular}{|cccccc|}
\hline $\begin{array}{c}\text { Energy } \\
(\mathrm{MeV})\end{array}$ & Ion & $\begin{array}{c}\text { Irradiation } \\
\text { Temperature }\end{array}$ & $\begin{array}{c}S_{e} \\
(\mathrm{keV} / \mathrm{nm}) \\
\text { for Ge/Cu }\end{array}$ & $\begin{array}{c}k \\
\left(\mathrm{~nm}^{4}\right)\end{array}$ & $\begin{array}{c}m \\
\left(\mathrm{~nm}^{6}\right)\end{array}$ \\
\hline 120 & $\mathrm{Au}$ & $77 \mathrm{~K}$ & $19.2 / 33$ & 74.1 & - \\
350 & $\mathrm{Au}$ & $77 \mathrm{~K}$ & $31.3 / 54.2$ & 144.9 & - \\
\hline 100 & $\mathrm{Ag}$ & $\mathrm{RT}$ & $16.7 / 28.9$ & 64.7 & 85.7 \\
120 & $\mathrm{Au}$ & $\mathrm{RT}$ & $19.2 / 33$ & 65.8 & 244.6 \\
140 & $\mathrm{Au}$ & $\mathrm{RT}$ & $21.2 / 36.5$ & 68.9 & 466.0 \\
\hline
\end{tabular}

In this paper, we attempt to discuss these experimental results, in the framework of the ITSM calculation. For simplicity, in the following sections, both Ge or a-Ge will refer to amorphous germanium.

\section{INELASTIC THERMAL SPIKE MODEL}

The ITSM is based on the numerical solution of the 
non-linear coupled differential equations governing heat diffusion on both electronic and lattice subsystems. The main output of the calculation is the time and space evolution of lattice temperature $T(r, t)$ (or what is equivalent to it : energy per atom $\left.E_{a t}(r, t)(\mathrm{eV} / \mathrm{at})\right) . r$ and $t$ are radial distance from ion path and time, respectively. For multilayers, heat diffusion in depth direction $(x)$ through one layer (material) to another due to temperature gradient is taken into account, as well. In this case lattice temperature profiles (or energy per atom $\left.E_{\text {at }}(x, r, t)\right)$ are obtained along the ion path. For more details about the basics of the thermal spike model see [21-25].

The melting process takes place if $E_{a t}(r, t)$ exceeds the energy necessary for melting $E_{a t m}$. This latter value corresponds to the energy necessary to bring the material to the melting temperature plus the latent heat of fusion $L_{f}$ :

$$
E_{\text {atm }}=\int_{T_{\text {intital }}}^{T_{\text {met }}} C_{s}(T) d T+L_{f}
$$

where $C_{s}(T)$ is the temperature dependence of the lattice specific heat taken from experimental results ([25] for $\mathrm{Cu}$ and [29] for $\mathrm{Ge})$. For RT irradiations, $E_{\text {atm }}(\mathrm{Cu})=$ $0.43 \mathrm{eV} / \mathrm{at}$ and $E_{\text {atm }}(\mathrm{Ge})=0.47 \mathrm{eV} / \mathrm{at}$. For low temperature irradiations, $E_{\text {atm }}(\mathrm{Cu})=0.47 \mathrm{eV} /$ at and $E_{\text {atm }}(\mathrm{Ge})=0.53 \mathrm{eV} /$ at.

\section{NUMERICAL RESULTS AND DISCUSSION}

Owing to the new experimental results of damage creation in $\mathrm{Ge}[4,5]$, in addition to those of Furuno et al. [3], we first reviewed the values of $\lambda$ which fit better these experimental results together. A slightly different value of $\lambda(4 \mathrm{~nm})$ compared with that $(4.5 \mathrm{~nm})$ obtained in [10], was deduced as illustrated in Fig.1. This value is far below that deduced by Shall et al. [26], $15 \mathrm{~nm}$, in crystalline germanium c-Ge, i.e. in good consistency with ( $\left.\lambda_{\text {amorphous }}<\lambda_{\text {crystalline }}\right)$. This means that a-Ge is much more sensitive to electronic excitation than c-Ge. Obviously, from [3] and Fig.1, a-Ge has a very low threshold $S_{\text {eth }}(<5 \mathrm{keV} / \mathrm{nm})$ whereas in c-Ge, tracks were observed for higher than $S_{\text {eth }}(37 \mathrm{keV} / \mathrm{nm})$ for cluster-ion irradiation $[1,2]$.

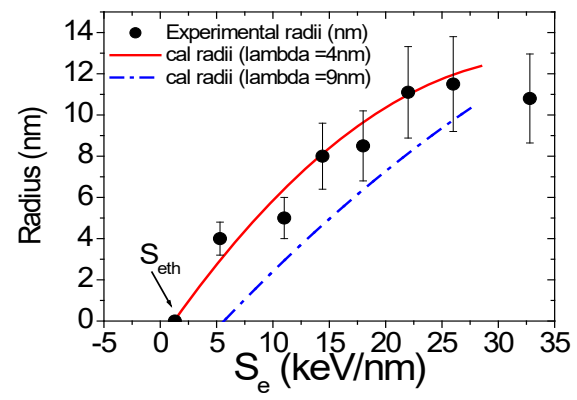

Fig.1 Calculated ion track radii versus $S_{e}$ for two different values of $\lambda(4 \mathrm{~nm}$ and $9 \mathrm{~nm})$. The experimental values of amorphous track radii (full circles) are reported in [3-5], with the error bars $(20 \%)$

In the following we will present the simulation results of the $\mathrm{Al}(30 \mathrm{~nm}) / \mathrm{Ge}(90 \mathrm{~nm}) / \mathrm{Cu}(90 \mathrm{~nm}) / \mathrm{Si}$ system for RT and $77 \mathrm{~K}$ irradiations. The calculations were performed using the following depth step, radial step and time step: $\Delta x=1 \mathrm{~nm}, \Delta r=1 \mathrm{~nm}$ and $\Delta t=5 \times 10^{-18} \mathrm{~s}$ respectively. The lattice thermal properties and electron-phonon coupling constant $\left(g=5 \times 10^{11}\right.$ $\mathrm{W} / \mathrm{cm}^{3} \mathrm{~K}$ ) of $\mathrm{Cu}$ were taken from [25]. We are interested in the behavior of $\mathrm{Ge}$ and $\mathrm{Cu}$ at the interface $\mathrm{Ge} / \mathrm{Cu}$. For all the irradiation energies, $S_{e}$ values for Ge (see Table I) are higher than $S_{\text {eth }}(5.3 \mathrm{keV} / \mathrm{nm})$ which means that lattice temperature of $\mathrm{Ge}$ will go much beyond the melting temperature. In contrast, bulk $\mathrm{Cu}$ is known to be very insensitive to $S_{e}$. Hence its lattice temperature remains far below its melting temperature $(1356 \mathrm{~K})$. In the case of bulk $\mathrm{Cu}$, for a value of $S_{e}=70 \mathrm{keV} / \mathrm{nm}$ (higher than that used here), the maximum lattice temperature was around $700 \mathrm{~K}$ [25]. In previous ITSM calculations [17,19], $\mathrm{Ni}$ (which is an insensitive metal like $\mathrm{Cu}$ ) was found to reach the melting temperature at the interface $\mathrm{Ni} / \mathrm{Ti}$ although $S_{e}$ value was much lower than $S_{\text {eth }}(\mathrm{Ni})$. The following sections will show the behavior of $\mathrm{Cu}$ in contact with $\mathrm{Ge}$ for low temperature $(77 \mathrm{~K})$ and room temperature irradiations.

\subsection{Low temperature $(77 \mathrm{~K})$ irradiations}

Fig. 2 shows the numerical results for $350 \mathrm{MeV} \mathrm{Au}$ ion irradiations at $77 \mathrm{~K}$. The maximum energy per atom versus the distance from surface for different radial distances is presented in Fig.2. As expected, the maximum energy per atom in the whole Ge layer is higher than the energy necessary for melt $\left(E_{\text {atm }}(\mathrm{Ge})\right)$, indicating that $\mathrm{Ge}$ undergoes solid-liquid phase transition. Far from the interface, the maximum energy per atom in $\mathrm{Cu}$ is approximately half the energy necessary for melt $\left(E_{\mathrm{atm}}(\mathrm{Cu})\right)$ which means that $\mathrm{Cu}$ remains solid. However, near the interface, $E_{\text {at }}$ of a thin layer of about $2 \mathrm{~nm}$ thickness of $\mathrm{Cu}$ exceeds $E_{\text {atm }}(\mathrm{Cu})$.



Fig.2 The maximum energy per atom versus the distance from surface for different radial distances under irradiation with 350 $\mathrm{MeV} \mathrm{Au}$ ions at $77 \mathrm{~K}$. The horizontal dashed dot lines indicate the melting energy per atom $E_{\mathrm{atm}}(\mathrm{Ge})$ and $E_{\mathrm{atm}}(\mathrm{Cu})$ for $\mathrm{Ge}$ and $\mathrm{Cu}$, respectively. The vertical dashed dot line shows the interface $\mathrm{Ge} / \mathrm{Cu}$.

The increase of the lattice energy (temperature) results from the heat flow from $\mathrm{Ge}$ to $\mathrm{Cu}$ due to temperature gradient at the interface. Fig.3.a and b show $E_{\text {at }}$ versus time in $\mathrm{Ge}$ and $\mathrm{Cu}$ at the interface, 
respectively. The radius of the molten phase is $9 \mathrm{~nm}$ in $\mathrm{Ge}$ and $5 \mathrm{~nm}$ in $\mathrm{Cu}$.


Fig.3 The energy per atom $E_{\text {at }}$ versus time for different radial distances, a) for $\mathrm{Ge}$ and b) $\mathrm{Cu}$ at the interface under $350 \mathrm{MeV}$ $\mathrm{Au}$ irradiation at $77 \mathrm{~K}$.

The numerical results of $120 \mathrm{MeV}$ Au ion irradiation at $77 \mathrm{~K}$ (not shown here) indicate that only a slice of 1 $\mathrm{nm}$ thickness of $\mathrm{Cu}$ next to Ge reaches the molten phase up to a radial distance of $2 \mathrm{~nm}$.

Time dependence of Ge molten phase at interface for $77 \mathrm{~K}$ irradiations is shown in Fig.4 (with those of RT irradiations). Molten radius and lifetime of $\mathrm{Ge}$ are higher for $350 \mathrm{MeV}$ than for $120 \mathrm{MeV}$ irradiation. We also note that molten $\mathrm{Ge}$, in both irradiations, remains much longer time than $\mathrm{Cu}$ (not shown here). Since only a very thin layer of $\mathrm{Cu}(1-2 \mathrm{~nm})$ melts next to a thick molten Ge layer, one may assume that the interface mixing results mainly from diffusion of $\mathrm{Cu}$ in molten $\mathrm{Ge}$. If we assume a mean radius value, $R_{m}=6 \mathrm{~nm}$, of the molten $\mathrm{Ge}$ at the interface in both $350 \mathrm{MeV}$ and $120 \mathrm{MeV}$ irradiations, one may estimate the molten phase lifetime from Fig. 4 as follows: $\tau_{l}=1 \times 10^{-12} \mathrm{~s}$, for $350 \mathrm{MeV}$ irradiation, $\tau_{2}=4 \times 10^{-13} \mathrm{~s}$, for $120 \mathrm{MeV}$ irradiation. Hence mixing rate can be evaluated from the formula given by Kraft [16]:

$$
k=\left(\pi R^{2}\right) 2 D \tau
$$

where $k$ is the mixing rate, $D$ is the diffusion coefficient and $\tau$ the molten phase lifetime. $R$ is the radius of the molten cylinder, through which atomic inter-diffusion occurs. If we assume that $D$ is constant in both cases;

$$
k_{2} / k_{1}=\left(R_{m}^{2} \tau_{2}\right) /\left(R_{m}^{2} \tau_{1}\right) \approx 2.45 \text {. }
$$

which is very close to the experimental mixing rates ratio $\left(\right.$ Table I): $k_{2 \exp } / k_{\text {lexp }}=144.9 \mathrm{~nm}^{4} / 74.1 \mathrm{~nm}^{4}=1.95$. If , in the Kraft formula, we combine experimental mixing rates with the calculated molten phase radius and lifetime, in both 350 and $120 \mathrm{MeV}$ irradiations, we get the following diffusion coefficients: $D_{1}=6.5 \times 10^{-3}$ $\mathrm{cm}^{2} / \mathrm{s}$ and $D_{2}=8.4 \times 10^{-3} \mathrm{~cm}^{2} / \mathrm{s}$, which are characteristic values of diffusion in liquid germanium $\left(10^{-4} \mathrm{~cm}^{2} / \mathrm{s}\right)$ $[27,28]$.

\subsection{RT irradiations}

As for RT irradiations (100 MeV Ag ions, 120 and $140 \mathrm{MeV} \mathrm{Au}$ ions (Table I)), the calculation results show that melting is induced from both sides of the interface $\mathrm{Ge} / \mathrm{Cu}$ in all the three irradiations. Fig. 4 shows the radius of molten $\mathrm{Ge}$ at the interface versus time for the different irradiations. It is clear that the molten phase lifetime increases with $S_{e}$. The influence of the irradiation temperature may be seen from comparing the $120 \mathrm{MeV} \mathrm{Au}$ ions case at RT and $77 \mathrm{~K}$ (Fig.4). Obviously the molten phase lifetime of Ge is higher at RT.

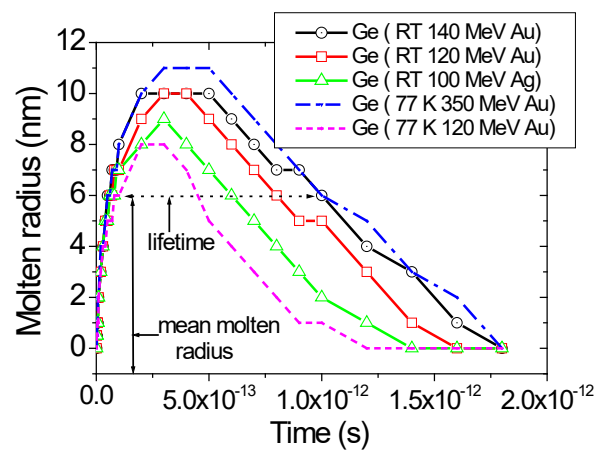

Fig.4 Molten phase radius versus time in Ge at the interface $\mathrm{Ge} / \mathrm{Cu}$ for $\mathrm{RT}$ and $77 \mathrm{~K}$ irradiations. The mean molten radius and lifetime for $350 \mathrm{MeV}$ at $77 \mathrm{~K}$ irradiation are illustrated.

Furthermore, comparison between $350 \mathrm{MeV}$ irradiation at $77 \mathrm{~K}$ and the three RT irradiations (see Fig.4) reveals that the mean molten radius and lifetime are higher for $350 \mathrm{MeV}$ irradiation at $77 \mathrm{~K}$. Therefore, assuming diffusion in molten phase, equation (1) will lead to higher mixing rates than in the RT irradiations. However, a much higher interface mixing at high fluences for RT irradiations as compared to $77 \mathrm{~K}$ irradiations was reported [21]. Indeed, the experimental results indicate a non-linear behavior of interface mixing with fluence for all RT irradiations. In fact, if we replot the difference of variances with fluence (RBS experimental results from [21]) for $77 \mathrm{~K}$ and RT (Fig.5), one can readily distinguish two different regimes. For low fluence values $\left(<3 \times 10^{13}\right.$ ions $\left./ \mathrm{cm}^{2}\right)$ a linear behavior for both $77 \mathrm{~K}$ and RT irradiations can be observed with a higher slope in case of $350 \mathrm{MeV}$ irradiation, indicating that mixing rate is the highest in this case. This is in good agreement with the calculation results and the molten phase mixing hypothesis.

When the fluence value increases beyond $3 \times 10^{+13}$ ions $/ \mathrm{cm}^{2}$, the difference of variances starts to increase rapidly for RT irradiations, whereas for low temperature irradiations it keeps increasing with the same rate (slope). In this fluence regime the molten phase mixing hypothesis fails to consider for the high interface mixing observed at RT irradiations. Therefore, an additional 
contribution to the mixing process at RT should be identified. In fact, Kumar et al. [21] suggested that mixing is driven by a chemical solid-state reaction at RT. As we mentioned earlier, SHI irradiation has been found to create voids in a-Ge, i.e. porous or low density regions. Therefore, it is suggested that, at RT where the atomic mobility is still effective, solid-state diffusion takes place within these low density regions. When increasing the fluence, the number of the created voids in a-Ge increases and, consequently, the contribution of solid-state diffusion increases.

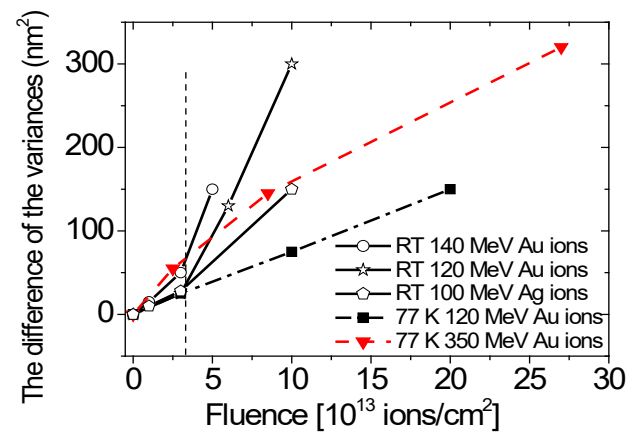

Fig. 5 The difference of the variances versus fluence for RT and $77 \mathrm{~K}$ irradiations replotted from [21].

\section{CONCLUSION}

The experimental results of swift heavy ion inducing mixing in $\mathrm{Cu} / \mathrm{a}-\mathrm{Ge}$ have been discussed in the light of the ITSM calculations. Transient thermal process has been evidenced in both sides of $\mathrm{Cu} / \mathrm{Ge}$ interface, indicating that mixing occurs in molten phase. However, for room temperature irradiations, we believe that solid-state diffusion contributes efficiently to the mixing phenomena through the porous structure of a-Ge created by SHI.

\section{Acknowledgements}

The authors thank M. Toulemonde and C. Dufour for permitting the use and modification of the source code for bulk and multilayer systems. H. A. was supported by JSPS-KAKENHI 20390032.

\section{References}

[1] W. Wesch, A. Kamarou, and E. Wendler, Nucl. Instrum. Methods Phys. Res., Sect. B 225, 111-128 (2004).

[2] A. Colder, O. Marty, B. Canut, M. Levalois, P. Marie, X. Portier, S.M.M. Ramos, and M. Toulemonde, Nucl. Instr. Meth Phys. Res, Sect. B 174, 491- 498 (2001).

[3] S. Furuno, H. Otsu, K. Hojou, and K. Izui, Nucl. Instr. Meth Phys. Res., Sect. B 107, 223-226 (1996).

[4] T. Bierschenk, B. Afra, M.D. Rodriguez, R. Giulian, C. Trautmann, S. Mudie, M.C. Ridgway, P. Kluth, Nucl. Instr. Meth Phys. Res., Sect. B 326, 113-116 (2014).

[5] M. C. Ridgway, T. Bierschenk, R. Giulian, B. Afra, M. D. Rodriguez, L. L. Araujo, A. P. Byrne, N. Kirby, O. H. Pakarinen, F. Djurabekova, K. Nordlund, M. Schleberger, O. Osmani, N. Medvedev, B. Rethfeld, and P. Kluth1, PRL 110, 245502 (1-5) (2013).
[6] T. Steinbach, C. S. Schnohr, W. Wesch, P. Kluth, R. Giulian, L. L. Araujo, D. J. Sprouster, and M. C. Ridgway, Phys. Rev. B 83, 054113 (2011).

[7] W. Wesch, C. S. Schnohr, P. Kluth, Z. S. Hussain, L. L.Araujo, R. Giulian, D. J. Sprouster, A. P. Byrne, and M. C. Ridgway, J. Phys. D 42, 115402 (2009).

[8] K. Gartner, J. Johrens, T. Steinbach, C. S. Schnohr, M.C. Ridgway, and W. Wesch, Phys. Rev. B 83, 224106 (2011).

[9] M. Toulemonde, C. Dufour and E. Paumier, Phys. Rev. B 46, 14362 (1992).

[10] M. Toulemonde, C. Dufour and E. Paumier and F. Pawlak, Mater. Res. Soc. Symp. Proc. 504, 99 (1999).

[11] M. Hayashi, M. Matsuda, T. Asozu, M. Sataka, M. Nakamura, A. Iwase, Nucl Instru and Meth in Physics Research B 314, 176-179 (2013).

[12] J. Teillet, F. Richomme, A. Fnidiki, M. Toulemonde, Phys. Rev. B 55, 11560 (1997).

[13] R. Leguay, A. Dunlop, F. Dunstetter, N. Lorenzelli, A. Braslau, F. Bridou, J. Corno, B. Pardo, J. Chevallier, C. Colliex, A. Menelle, J.L. Rouviere, L. Thome, Nucl. Instr. and Meth. B 122, 481-502 (1997).

[14] Ph. Bauer, C. Dufour, C. Jiaouen, G. Marchal, J. Pacaud, J. Grilhe, J.C. Jousset, J. Appl. Phys. 81, 116 (1997).

[15] D.K. Avasthi, W. Assmann, H. Nolte, H.D. Mieskes, H. Huber, E.T. Subramaniyam, A. Tripathi, S. Gosh, Nucl. Instr. and Meth. B 156, 143 (1999).

[16] S. Kraft, B. Schattat, W. Bolse, S. Klaumünzer, F. Harbsmeier, A. Kulinska, A. Löffle, J. Appl. Phys. 91, 1129 (2002).

[17] Z.G. Wang, C. Dufour, S. Euphrasie, M. Toulemonde, Nucl. Instr. and Meth. B 209, 194-199 (2003).

[18] A. Chettah, Z.G. Wang, M. Kac, H. Kucal, A. Meftah, M. Toulemonde, Nucl. Instr. and Meth. B 245, 150-156 (2006).

[19] A. Chettah, H. Kucal, Z.G. Wang, M. Kac, A. Meftah, M. Toulemonde, Nucl. Instr. and Meth. B 267, 2719-2724 (2009).

[20] A. Chettah, H. Amekura, R. Baeker, H. Kucal, Y. Takeda, M. Matsuda, and A. Iwase, Phys. Status Solidi C 12, No. 1-2, 102-106 (2015).

[21] S. Kumar, R.S. Chauhan , D.C. Agarwal , M. Kumar, A. Tripathi ,W. Bolse , D.K. Avasthi, Nucl. Instr. and Meth. B 266, 1759-1763 (2008).

[22] C. Dufour 1993, PhD thesis CEA-R-5638

[23] A. Chettah 2006, PhD thesis (Université de skikda, Algeria).

[24] M. Toulemonde, C. Dufour, A. Meftah, E. Paumier, Nucl. Instr. and Meth. B 166\&167, 903-912 (2000).

[25] Z.G. Wang, C. Dufour, E. Paumier, M. Toulemonde, J. Phys Condens. Mater. 6, 6733-6750 (1994).

[26] M. Sall, I. Monnet, F. Moisy, C. Grygiel, S. Jublot-Leclerc, S. Della-Negra, M. Toulemonde, E. Balanzat, J Mater Sci, 50, 5214-5227 (2015).

[27] V. Hugouvieux, E. Farhi, M. Johnson, F. Juranyi. F. Bourges and W. Kob, Phys. Rev. B 75, 104208 (2007).

[28] T. Som, J. Ghatak, O. P. Sinha, R. Sivakumar, and D. Kanjilal, J. Appl. Phys. 103, 123532 (2008).

[29] W. Szyszko, F. Vega and C.N. Afonso, Appl. Phys. A 61, 141-147 (1995).

(Received January 28, 2016; Accepted March 22, 2016; Published Online September 1, 2016) 